\title{
Journal of Marine Science: Research \& Development
}

\section{Corals at the EDGE of Existence}

Crabbe MJC $^{1,2^{*}}$

${ }^{1}$ Department of Zoology, University of Oxford, Tinbergen Building, South Parks Road, Oxford, OX1 3PS, UK

${ }^{2}$ Institute of Biomedical and Environmental Science and Technology, Technologies and Science, University of Bedfordshire, Park Square, Luton, LU1 3JU, UK

*Corresponding author: Crabbe MJC, Department of Zoology, University of Oxford, Tinbergen Building, South Parks Road, Oxford, OX1 3PS, UK, Tel: +44 1865 271234; E-mail: james.crabbe@zoo.ox.ac.uk

Received date: 11 September, 2016; Accepted date: 12 September, 2016; Published date: 16 September, 2016

Copyright: (c) 2016 Crabbe MJC. This is an open-access article distributed under the terms of the Creative Commons Attribution License, which permits unrestricted use, distribution, and reproduction in any medium, provided the original author and source are credited.

\section{Editorial}

There are numerous human and environmental challenges to coral reefs that leave many species of scleractinian corals globally threatened. The EDGE of Existence (Evolutionarily Distinct and Globally Endangered) programme commenced in 2007 at the Zoological Society of London (ZSL). The purpose of the programme was to focus resources for science and conservation on species where little research had been done, or where there were no conservation plans. The programme was developed to support EDGE Fellows who came from, and were based, in the countries where the EDGE species existed. So far, 58 Fellows have been supported, in 33 countries. The Fellowship lasts 2 years, and provides training to develop science and conservation techniques, including outreach and policy development. A grant enables initial implementation of the project. The EDGE programme aims to train future leaders in conservation science. In 2011 the programme was expanded from mammal, amphibian, reptile and bird species to include coral reefs. Specific training in coral reef biology, taxonomy and ecology is provided, together with SCUBA training if necessary. Marine conservationists are able to target conservation projects directed to specific species in Africa, Asia and the Americas.

EDGE species are selected using an 'Evolutionary Distinctiveness' (ED) score, from phylogenetic trees, and a Globally Endangered (GE) score for each species based on the IUCN Red List Categories (Critically Endangered, Endangered, Vulnerable, Near Threatened and Least Concern). A key element of the Fellowship programme is science linked to capacity-building and education. For example, Nikita ShielRolle, EDGE Fellow and director of Young Marine. Explorers, works to empower youth through coral conservation and quantifying threats and determining the distribution, both historical and current, of Dendrogyra cylindrus in the Bahamas.
A new cohort of EDGE Fellows is trained each year, so EDGE Fellows can respond reasonably quickly to acute threats. For example, in the recent bleaching event on the Great Barrier Reef, where only 7\%, of the 911 surveyed reefs showed no signs of bleaching, EDGE corals such as Poritipora paliformis can form the basis of conservation action. Over 50 million years ago this coral diverged from its closest relatives, so it is both evolutionarily distinct and globally endangered [1-3].

Applications for EDGE Fellows must be from early career scientists and conservationists resident in the country where the species, part of a curated list is from. Often such applications link to senior scientists in other countries, so that EDGE Fellows receive international support and training.

Loss of EDGE coral species would significantly reduce biodiversity in marine environments worldwide, and would also endanger the livelihoods of people who depend on them. This is an important programme that involves both marine science and marine conservation, and deserves global support.

Citation: Crabbe MJC (2016) Corals at the EDGE of Existence. J Marine Sci Res Dev 6: e143. doi: 10.4172/2155-9910.1000e143

\section{References}

1. Crabbe MJC (2015) How effective are Marine Protected Areas (MPAs) for coral reefs? J Marine Sci Res Dev 5: e134.

2. EDGE of Existence.

3. Curnick DJ, Head C, Huang D, Crabbe MJC, Gollock M, et al. (2015) Setting evolutionary-based conservation priorities for a phylogenetically data-poor taxonomic group (Scleractinia). Animal Conservation 18: 303-312. 